\title{
Scholarly debate in the pages of Coral Reefs
}

\author{
Rolf P. M. Bak
}

Published online: 8 January 2009

(C) Springer-Verlag 2009

In July 2008, I took over as Editor in Chief of Coral Reefs from former Editor Professor Barbara Brown and, thanks to her efforts, have inherited an editorial process that is running smoothly. The journal is in steady waters. It is as if we are having a picnic in the lagoon, not worrying too much about the deep dive we are going to make on the fore reef, in a couple of hours. Nevertheless we will soon have to go out and confront the risks of that spectacular fore reef dive.

What I mean by this metaphor is that we have to confront the more challenging and controversial questions in coral reef research head on. Of course, Coral Reefs will continue to emphasize papers about observations, hypotheses, experiments and models in reef research. But, in addition, I would like to rough things up a bit. We should not be afraid to differ in opinion on scientific issues, especially those such as global change which are potentially volatile. Scientific controversies should be aired openly, and I look forward to and welcome scholarly, respectful debate for future issues of Coral Reefs. And I emphasize scholarly, because Coral Reefs is not the place for advocacy.
What I hear sometimes is that differences in opinion within the scientific community will be exploited by decision makers to take no steps where they are needed. We have a duty as reef researchers to help to develop responsible policies consistent with available scientific information. Part of the process involves questioning accepted scientific dogma and providing reasoned counter arguments based on valid scientific studies. My vision is that in the coming years Coral Reefs will reflect both the certainties and the doubts that confront us.

It is the duty of the Editorial Staff of Coral Reefs to advance publication of scholarly research that helps us understand reefs and the changes that will occur in the global environment. There will be room for discussion because asking questions, which is the genesis of discussion, is an essential part of the scientific tradition. Controversy will stimulate close scrutiny. I invite you to comment, using either your own research data or a scientific interpretation of available literature, to improve our understanding of coral reef ecosystems.

Do include a provocative manuscript in the bunch that you are thinking of publishing in Coral Reefs!
R. P. M. Bak ( ()

Editor in Chief

Coral Reefs Editorial Office, Netherlands Institute for Sea Research, P.O. Box 59, 1790 AB Den Burg, The Netherlands

e-mail: CoralReefJournal@nioz.nl 